\title{
Tweetalige Frasewoordeboek/Bilingual Phrase Dictionary: 'n Fokus op funksies en enkele probleemareas
}

Anna Nel Otto, Departement Afrikaans, Universiteit Vista, Port Elizabeth, Republiek van Suid-Afrika (OTTO-AN@pelican.vista.ac.za)

Opsomming: Hierdie woordeboek deur P.A. Joubert sal bespreek word aan die hand van die volgende aspekte: die volledigheid van die woordeboek, met inagneming van die teikengebruiker en die beginsels van outentisiteit en tipiesheid, die verwerking van woordeboekinligting om gebruikers se potensiële vrae te beantwoord, die mate waarin inligting vinnig opgespoor en maklik ontsluit kan word, en die formaat en redigering van die woordeboek.

Daar word geargumenteer dat dié woordeboek redelik volledig is, maar weens die gebrek aan 'n sistematiese teoretiese onderbou tog enkele leemtes het. Tipiesheid word soms ingeboet deur die opname van baie formele, weinig gebruiklike of verouderde frases, wat ook nie as sodanig geëtiketteer is nie. Inligting kan oor die algemeen maklik opgespoor word, maar vollediger aanduidings in die gids tot die woordeboek oor die plasing van multileksikale lemmas sal opspoorbaarheid verder verhoog. Die formaat en redigering van die woordeboek is goed.

Frasewoordeboeke vervul 'n belangrike funksie deurdat daar nie weens ' $n$ hoë inligtingsdigtheid, soos in algemene tweetalige woordeboeke, na inligting oor frases gesoek hoef te word nie. Van 'n aktiewe frasewoordeboek sou 'n mens egter soms meer gebruiksleiding verwag in die vorm van veral voorbeeldsinne en die konsekwente gebruik van etikette.

Sleutelwoorde: TWEETALIGE FRASEWOORDEBOEK, VOLLEDIGHEID, OUTENTISITEIT, TIPIESHEID, OPSPOORBAARHEID, GEBRUIKERSVRIENDELIKHEID, VOORBEELDSINNE, ETIKETTE, REDIGERING, MULTILEKSIKALE LEMMA, KOLLOKASIE, FRASE

\begin{abstract}
Tweetalige Frasewoordeboek/Bilingual Phrase Dictionary: A Focus on Functions and a Few Problem Areas. This dictionary by P.A. Joubert will be discussed with reference to the following aspects: the completeness of the dictionary, with due allowance for the target users and the principles of authenticity and representativeness, the processing of dictionary information in order to answer the potential questions of users, the degree to which information can be accessed quickly and easily, and the format and editing of the dictionary.

It will be argued that though this dictionary is fairly complete, it has shortcomings because of a lack of systematic-theoretical grounding. Representativeness is at times sacrificed by including phrases which are very formal, used infrequently or being obsolete, and which are also not labelled as such. In general information can easily be retrieved but in instances where multilexical lemmata are involved, retrievability could be enhanced by more detailed indications of placement in the guide to the dictionary. The format and editing of the dictionary is good.

Other than general bilingual dictionaries with their high information density, phrase dictionaries play an important role in that information about phrases does not need to be sought. One
\end{abstract}


would however sometimes expect more usage guidance from an active phrase dictionary in the form of especially example sentences and a consistent use of labels.

Keywords: BILINGUAL PHRASE DICTIONARY, COMPLETENESS, AUTHENTICITY, REPRESENTATIVENESS, RETRIEVABILITY, USER-FRIENDLINESS, EXAMPLE SENTENCES, LABELS, EDITING, MULTILEXICAL LEMMA, COLLOCATION, PHRASE

\section{Inleiding}

By die beoordeling van enige woordeboek kan daar na minstens vier aspekte gekyk word:

- die volledigheid van die woordeboek, met inagneming van die teikengebruiker en die beginsels van outentisiteit en tipiesheid,

- die verwerking van die woordeboekinligting om gebruikers se potensiële vrae te beantwoord,

- die mate waarin inligting vinnig opgespoor en maklik ontsluit kan word, en

- die formaat en finale redigering van die woordeboek.

\subsection{Die volledigheid van die woordeboek}

Die volledigheid al dan nie van enige woordeboek moet gemeet word aan die tipe woordeboek en die teikengroep vir wie die woordeboek opgestel word. Hierbenewens geld twee algemene beginsels wat vir alle woordeboeke geld, naamlik outentisiteit en tipiesheid. Svensén (1993: 40-42) verduidelik hierdie twee terme soos volg.

\section{Outentisiteit}

Baie woordeboeke word deur leksikograwe opgestel wat hul seleksie van die woordeskat slegs baseer op hul eie taalvermoëns. Hierdie metode word as gevaarlik bestempel. Die seleksie van woordeboekmateriaal moet outentiek wees, d.w.s. dit moet slegs linguistiese materiaal bevat wat werklik bestaan. Onafhanklike bronne moet gebruik word om die outentisiteit van linguistiese materiaal te bevestig. Getuienis word ongelukkig meestal uit geskrewe bronne verkry. In hierdie verband sê Svensén die volgende:

"Evidence" normally means "evidence from written sources". Unfortunately, the spoken language makes up by far the larger part of all linguistic production, whereas by far the larger part of all evidenced linguistic production is in writing. The requirement of authenticity is therefore unfavourable to several of those forms of the language which the user in many cases might want information about, such as everyday colloquial speech, slang, dialect, and technical jargon. 
Verder waarsku Svensén (1993: 41) teen die opname van "spookwoorde", d.i. woorde wat in woordeboeke bestaan, maar nie in die werklikheid nie. Dit word nog moeiliker om lewenseg te wees wanneer grammatiese en semantiese inligting geillustreer moet word. Wanneer die leksikograaf ' $n$ bepaalde insig by die gebruiker wil tuisbring, is dit egter volgens Svensén (1993: 41) geregverdig om byvoorbeeld poëme te gebruik wat afgelei is van outentieke voorbeelde.

\section{Tipiesheid}

Dit is nie net noodsaaklik om outentieke woorde en uitdrukkings in die woordeboek op te neem nie. 'n Verdere vereiste is dat elke woord of uitdrukking gereeld genoeg gebruik moet word in die taal. Svensén (1993: 42) verduidelik tipiesheid soos volg:

Representativeness ... means that the word or expression occurs with a certain frequency in the general use of the language. This condition of representativeness primarily concerns active dictionaries.

In die bespreking oor die tipe woordeboek, sy doel en teikengebruikers, en die gedeelte oor die verwerking van die inligting hieronder, sal aangetoon word dat die Tweetalige Frasewoordeboek/Bilingual Phrase Dictionary (voortaan TFW/ $B P D$ ) verbeter sou kon word deur meer outentieke en tipiese frases in te sluit, aangesien hierdie woordeboek ten doel het om as aktiewe woordeboek praktiese gebruiksleiding te verskaf.

\subsection{Die tipe woordeboek, sy doel en teikengebruikers}

Die eerste vraag wat ' $n$ mens in hierdie verband kan vra, is: wat is ' $n$ frasewoordeboek en aan watter kriteria behoort 'n tweetalige frasewoordeboek gemeet te word? Schemann (1989: 1019 e.v.) wys soos volg op die gebrek aan 'n algemeen geldige antwoord op hierdie vraag:

Mir ist kein einziges phraseologisches Wörterbuch bekannt, das (a) sich auf ein Material beschränkte, welches von irgendeiner Definition des phraseologischen Ausdrucks in seinem Umfang exakt abgesteckt werden könnte; und das (b) in den Definitionen, die (in den Vor- oder auch Nachworten) gegeben werden, systematisch-kohärent wäre.

Volgens Schemann (1989: 1021) is die enigste sinvolle vraag wat 'n mens oor hierdie woordeboektipe kan stel: oor watter frase gaan dit in hoofsaak? En die antwoord sal ten nouste saamhang met die doel van die woordeboek.

Verder wys Schemann (1989: 1021-1022) op die gevaar van 'n frasewoordeboek wat nie hou by die algemeen geldende kriterium dat ' $n$ frase 'n kontekstueel gebonde item moet wees en nie ' $n$ vrye verbinding nie. 
In die TFW/BPD word bloot in die voorwoord genoem dat die woord "frase" in die titel van die woordeboek in sy ruimste betekenis gebruik word. In die HAT word die woord "frase" gedefinieer as: "groep samehangende woorde wat ' $n$ deel van 'n sin vorm, maar geen volsin nie; sinsnede". In die TFW/BPD word verder genoem dat die begrip "frase" 'n verskeidenheid soorte woordgroepe omvat, wat soms duidelikheidshalwe tot volsinne uitgebrei word. Hierdie woorde toon hoe woorde in Afrikaans en in Engels saam ingespan word. Boonop is ' $n$ aantal spreekwoorde opgeneem. Die moontlike gebruike van die woordeboek word verder soos volg aangedui: "Antwoorde word verskaf op vrae soos wat die gepaste werkwoorde, voorsetsels, byvoeglike naamwoorde of bywoorde in bepaalde gevalle is, wat die woordorde is en of ' $n$ lidwoord gebruik word of nie."

En in 'n volgende paragraaf word gesê: "Die woordeboek is bedoel as 'n praktiese gebruiksgids waarin naslaners maklik die woordkombinasies kan vind waarmee hulle hulle in die twee tale kan uitdruk; dit kan hulle ook help om die twee tale se onderskeie maniere om iets te sê nie met mekaar te verwar nie."

Met so 'n pragmatiese uitgangspunt is daar nie fout te vind nie. Hanks (1979: 33) het immers gesê: "When theory comes into lexicography, all too often common sense goes out." Die gevaar bestaan egter dat as daar nie ' $n$ teoretiese onderbou is nie, daar aan konsekwentheid ingeboet kan word, wat daartoe kan lei dat belangrike inligting per ongeluk weggelaat word of dat die gebruiker verwar kan word deur 'n inkonsekwente aanbod.

Hoewel uitgewers gewoonlik beweer dat die toeligtingsgedeelte so kort moontlik moet wees, aangesien die meeste gebruikers dit in elk geval nie lees nie, is dit noodsaaklik dat daar in die toeligtingsgedeelte baie duidelik uitgespel moet word watter tipes frases opgeneem word en wat die kriteria vir opname was, anders sal die gebruikers nie weet of die woordeboek aan hulle behoeftes behoort te voldoen of nie. Dit is nie nodig om die gebruiker met teoretiese kennis te oorlaai nie: 'n voorbeeld of twee van elke tipe sal dadelik aan hom/haar 'n beeld gee van die omvang van die woordeboek.

Bogenoemde probleme sal vervolgens aan die hand van enkele voorbeelde bespreek word.

In die BBI Dictionary word kollokasies konsekwent op grond van geïdentifiseerde patrone opgeneem. Dit is ook 'n tipe "frase" wat die TFW/BPD insluit, maar anders as in die BBI word kollokasies nie op 'n konsekwente wyse opgeneem nie.

In die BBI word die positiewe en die negatiewe konsekwent by werkwoorde aangedui. Die woord aanbeveling kan byvoorbeeld met bekragtig en verwerp verbind. Hierdie inligting ontbreek by aanbeveling in die TFW/BPD. Op 'n soortgelyke wyse ontbreek toestaan en afkeur / afwys / teenstaan byvoorbeeld by die woord aansoek. 
In die geheel beskou kan nogtans gesê word dat die woordeboek se makrostruktuur, wat volledigheid betref, aan die meeste gebruikers se verwagtinge behoort te voldoen.

\section{Die verwerking van die inligting om gebruikers se potensiële vrae te beantwoord}

\section{Voorbeeldsinne en etikette}

In die voorwoord word aangedui dat die woordeboek 'n praktiese gebruiksgids is en dit veronderstel dat dit bedoel is om 'n aktiewe woordeboek te wees. In 'n aktiewe woordeboek moet die gebruiksleiding so volledig wees dat die gebruiker sal weet hoe om elke frase op 'n gepaste wyse te gebruik. Dit is te betwyfel of die gebruiksleiding wat wel verskaf word, in alle gevalle aan gebruikers se behoeftes sal voldoen. Enkele voorbeelde ter illustrasie:

Onder die woord baadjie verskyn o.a. die frase baadjie uittrek* met as ver-

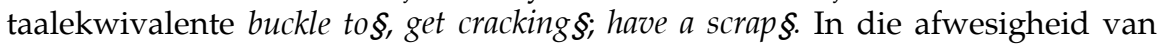
voorbeeldsinne kan gebruikers wat nie goed vertroud is met Afrikaans en/of Engels nie, foutiewe aannames maak oor die gebruik van hierdie uitdrukkings. Die aanwending van minstens die etiket "figuurlik (fig.)" sou hier noodsaaklike gebruiksleiding kon verskaf. Daar is ook enkele ander gevalle waar 'n mens graag 'n voorbeeldsin sou wou sien. By die frase he has his work cut out to ... sou 'n mens graag ' $n$ voorbeeldsin wou hê, wat kan aandui hoe hierdie frase voltooi kan word.

Die grootste probleem met die verwerking van inligting in hierdie woordeboek lê op die terrein van etiketgebruik. Daar is baie gevalle waar 'n uitdrukking aangedui word as "informeel", maar waar "minder gebruiklik"/ "verouderend" meer gepas sou wees. (Die tekens * en $\S$ dui in die TFW/BPD aan dat ' $n$ frase "informeel" is in onderskeidelik Afrikaans en Engels.) Vergelyk enkele voorbeelde:

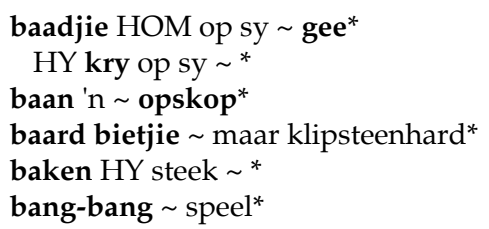

In ander gevalle, waar 'n mens die etiket "formeel", "minder gebruiklik" of "weinig gebruiklik" sou verwag, word geen etiket verskaf nie. Die gebruiker sal graag verstaan wil word en moet gevolglik gebruiklike vertaalekwivalente kry wat vir iemand in die jaar 2001 in Suid-Afrika duidelik sal wees. Dit is te betwyfel of selfs moedertaalsprekers van Afrikaans mekaar sal verstaan indien die volgende vertaalekwivalent gebruik sal word vir "make s.o. a present of 
s.t.": iem. iets kado gee. Die nuutste uitgawe van die HAT dui tereg aan dat die woord kado weinig gebruiklik is. Vergelyk ook die volgende voorbeelde:

\section{baan breek}

iem. moet die bed hou

iem. iets in bedenking gee

die bedrieër bedroë

iem. laat beesvel ry

befaamd wees om/vir

goed beklant wees

HY het SY bekoms van iets

HY bekla HOM oor iets

HY staan onder die besemstok

beslaan raak ( $b v$. ' $n$ bril)

'n beswaar billik/handhaaf

' $n$ betaling voldoen

dit behoef geen betoog nie dat -

na bevind van sake

iem. se duur bevogte -

\section{Grammatiese inligting}

Taal is nie staties nie, gevolglik behoort die leksikograaf ook erkenning te gee aan grammatiese veranderinge wat reeds ingeburger is. Al-Kasimi (1983: 109) noem o.a. die volgende kriterium wat in tweetalige woordeboeke behoort te geld: "Are the recent findings of modern linguistics in phonology, grammar, and semantics applied in the dictionary?" ' $n$ Mens sou hierdie kriterium nie net op taalteorie nie, maar ook op die taalpraktyk van toepassing kon maak. In hierdie verband sou die leksikograaf byvoorbeeld erkenning moes gee aan die verlies aan wederkerendheid by sommige werkwoorde in Afrikaans. Ponelis (1979: 228) het reeds in 1979 daarop gewys dat wederkerendheid by 'n klompie werkwoorde, veral in die omgangstaal, verlore gaan. Dit is gevolglik nie duidelik waarom wederkerendheid in die volgende gevalle voorkom nie:

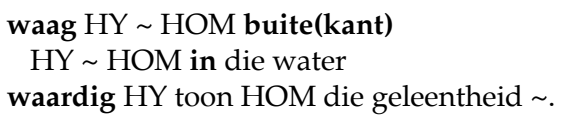

In die voorwoord word vermeld dat die korrekte woordorde aangedui word. Oor die algemeen verskaf die volgorde waarin die woorde van die frases verskyn wel 'n korrekte aanduiding van die woordorde, maar dit kan nie konsekwent as 'n riglyn gebruik word nie. Dit is in elk geval baie moeilik om die korrekte woordorde aan te dui sonder volsinne. Hiermee enkele voorbeelde:

wag die wag aflos die wag betrek 


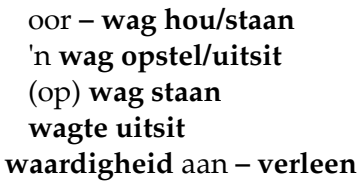

\section{Die mate waarin inligting vinnig opgespoor en maklik ontsluit kan word}

Hierdie kriterium hou verband met die konsep "gebruikersvriendelikheid" waarop toenemend klem gelê word deur leksikograwe. In hierdie verband sê Kromann, et al. (1991: 2713): "The user aspect ... involves consideration on the part of the lexicographer for the dictionary's target group, its needs and competence, and the types of user situations that occur."

In die voorwoord van die TFW/BPD word die teikengebruiker nie duidelik gespesifiseer nie, maar daar kan waarskynlik aanvaar word dat die woordeboek veral op taalpraktisyns gerig is. Indien dit die geval is, behoort die gebruikers oor die algemeen nie probleme te hê met die opspoor en ontsluiting van inligting nie. Kruisverwysings in die woordeboek dra by tot 'n gebruikersvriendelike aanbod. By die woord waarheid is daar byvoorbeeld 'n verwysing na suigeling en by mond is daar ook 'n verwysing na suigeling.

Die gebruikersvriendelikheid van die woordeboek sou verder verhoog kon word deur in die toeligtingsgedeelte aan te dui onder watter woord(e) multileksikale lemmas opgeneem word. Dit is veral belangrik, aangesien die plek van aanduiding omstrede is. (Vergelyk Gouws (1989: 97-108) vir 'n bespreking van die voor- en nadele van verskillende plasings.) Enkele voorbeelde sal ter illustrasie bespreek word.

Die uitdrukking uit die mond van die suigeling sal jy die waarheid hoor is hierbo by implikasie genoem. Hoewel dit die gebruiker help dat daar by verskeie lemmas verwysings is na suigeling, waar die vertaalekwivalent verskyn, sou dit die gebruiker nog meer gehelp het as daar in die toeligting 'n aanduiding was van die woord waaronder 'n vaste uitdrukking opgeneem word. Die meeste gebruikers sou waarskynlik onder die eerste selfstandige naamwoord in die uitdrukking, naamlik mond, soek vir die vertaalekwivalent, maar dan verder moet blaai na suigeling toe.

By walgens verskyn die frase tot walgens toe met die vertaalekwivalente to satiety; ad nauseam. Aan die Engelse kant is ad nauseam nie opgeneem onder ad nauseam by die letter A nie, maar wel by die letter $\mathrm{N}$ onder nauseam. Gebruikers van die HAT is byvoorbeeld gewoond daaraan om leenwoordgroepe alfabeties na te slaan. Interessant genoeg verskyn ad nauseam glad nie aan die Afrikaanse kant van die woordeboek nie.

Die omkeerbaarheidsbeginsel (vgl. Gouws 1989: 162) word ook byna deurgaans toegepas. ' $n$ Uitsondering is teëgekom by die uitdrukking hy staan onder 
die besemstok wat aan die Afrikaanse kant vertaal word met he is henpecked, maar laasgenoemde uitdrukking verskyn nie aan die Engelse kant nie.

\section{Die formaat en finale redigering van die woordeboek}

Al-Kasimi (1983: 112) noem drie kriteria wat verband hou met die voorkoms van 'n woordeboek, naamlik:

- 'n aangename en aantreklike formaat,

- goeie drukwerk en maklik vindbare inskrywings, en

- min tipografiese foute.

Hierby sou ' $\mathrm{n}$ mens bekostigbaarheid en hanteerbaarheid as bonusse kon byvoeg.

Die TFW/BPD het beslis 'n aantreklike voorkoms en die drukwerk en uiteensetting is besonder netjies. Die woordeboek verskaf ook goeie waarde vir geld en kan boonop maklik rondgedra of ingepak word. Tipografiese foute is ook tot die minimum beperk en die gebruiker sal dit dadelik as sodanig herken, byvoorbeeld die woord be wat herhaal word by die Guide: EnglishAfrikaans, die woord to wat herhaal word by die Engelse vertaalekwivalent onder die lemma berus en die woord idea wat weggelaat is in die frase not have the faintest / foggiest idea onder die lemma benul.

\section{Gevolgtrekking}

Die waarde van die TFW/BPD is geleë in die groot versameling gebruiklike frases wat in een woordeboek saamgevat is, sonder dat die gebruiker deur 'n magdom inligting moet worstel om 'n bepaalde frase op te spoor, soos wat die geval dikwels in algemene tweetalige woordeboeke is. Hierdie woordeboek sal verder verbeter kan word deur 'n vollediger toeligtingsgedeelte, deur slegs te konsentreer op gebruiklike frases, deur etikette op 'n sistematiese wyse te gebruik en deur meer volsinvoorbeelde naas die frases in te sluit.

\section{Verwysings}

Al-Kasimi, Ali M. 1983. Linguistics and Bilingual Dictionaries. Leiden: E.J. Brill.

Benson, M., E. Benson en R. Ilson. 1986. The BBI Combinatory Dictionary of English. A Guide to Word Combinations. Amsterdam/Philadelphia: John Benjamin.

Gouws, R.H. 1989. Leksikografie. Pretoria/Kaapstad: Academica.

Hanks, P. 1979. To What Extent Does a Dictionary Definition Define? Hartmann, R.K.K. (Red.). 1979: 32-38.

Hartmann, R.K.K. (Red.). 1979. Dictionaries and their Users: Proceedings of the 1978 BAAL Seminar on Lexicography. Exeter: University of Exeter. 
Hausmann, F.J., O. Reichmann, H.E. Wiegand en L. Zgusta (Reds.). 1989-1991. Wörterbücher: Ein internationales Handbuch zur Lexikographie. / Dictionaries: An International Encyclopedia of Lexicography. / Dictionnaires: Encyclopédie internationale de lexicographie. Berlyn/New York: Walter de Gruyter.

Joubert, P.A. 1997. Tweetalige Frasewoordeboek Afrikaans-Engels: 'n Praktiese Gebruiksgids./ Bilingual Phrase Dictionary English-Afrikaans: A Practical Usage Guide. Kaapstad: Pharos.

Kromann, Hans-Peder, T. Riiber en P. Rosbach. 1991. Principles of Bilingual Lexicography. Hausmann, F.J. et al. (Reds.). 1989-1991: 2711-2728.

Odendal, F.F. en R.H. Gouws. 2000. HAT Verklarende Handwoordeboek van die Afrikaanse Taal. Midrand: Perskor.

Ponelis, F.A. 1979. Afrikaanse Sintaksis. Pretoria: Van Schaik.

Schemann, H. 1989. Das phraseologische Wörterbuch. Hausmann, F.J. et al. (Reds.). 1989-1991: 1019-1032.

Svensén, B. 1993. Practical Lexicography. Principles and Methods of Dictionary-Making. Oxford/New York: Oxford University Press. 